\title{
Cell-specific Synergic Effect of Cimicifugoside on Cytotoxicity of Methotrexate
}

\author{
Ayako Yawata, ${ }^{a, b}$ Saki Kimura, ${ }^{b}$ Misato Matsushita, ${ }^{b}$ Takehiro Mochizuki, ${ }^{b}$ \\ Toshiyuki Chikuma, ${ }^{b}$ Hiroshi Hojo, ${ }^{b}$ and Yasumitsu Ogra ${ }^{*, a, c}$ \\ ${ }^{a}$ Laboratory of Chemical Toxicology and Environmental Health, ${ }^{b}$ Laboratory of Hygienic Chemistry and ${ }^{c}$ High Technology Research \\ Center, Showa Pharmaceutical University, 3-3165 Higashi-Tamagawagakuen, Machida, Tokyo 194-8543, Japan
}

(Received March 12, 2011; Accepted April 4, 2011; Published online April 6, 2011)

\begin{abstract}
Cimicifugoside is a triterpenoid originating from the rhizomes of Cimicifuga simplex, and acts to inhibit the subcellular transport of nucleosides. Cimicifugoside, when used in combination with methotrexate, showed a cellspecific synergic effect on the promonocytic leukemia cell line U937, but not on the chronic myelogenetic leukemia cell line K562. Thymidine uptake was more severely inhibited by cimicifugoside in a dose-dependent fashion in U937 than in K562. The mRNA expression of one of the equilibrative $\mathrm{Na}^{+}$-independent nucleoside transporters, ENT2, was lower in U937 than in K562. This suggests that the thymidine uptake by ENT2 of U937 is more severely affected by cimicifugoside than that of K562, resulting in a decrease in DNA synthesis by methotrexate. In addition, cimicifugoside more efficiently stimulated the activity of thymidine kinase (TK) in K562 than in U937, suggesting that K562 resisted the decrease in DNA synthesis caused by the inhibition of nucleoside transporters. Cimicifugoside bifunctionally potentiated the cell-specific cytotoxicity of methotrexate by inhibiting ENT2 and activating TK.
\end{abstract}

Key words — cimicifugoside, methotrexate, nucleoside, thymidine kinase, nucleoside transporter

\section{INTRODUCTION}

Nucleotides can be synthesized de novo or recycled through a salvage pathway in vivo. In the salvage pathway, nucleotides are synthesized from extracellular nucleosides and/or nucleobases. The plasma membrane transport of nucleosides is concerned with both the physiology and pharmacology of mammalian cells. Most mammalian cells simultaneously express several nucleoside transporters (NTs) in the plasma membrane. NTs possess certain differences in $\mathrm{Na}^{+}$-dependency, permeation selectivity, and inhibitor sensitivity. NTs can be divided into two major classes: concentrative $\mathrm{Na}^{+}$dependent nucleoside transporters (CNTs) and equilibrative $\mathrm{Na}^{+}$-independent nucleoside transporters (ENTs). CNTs are nucleoside $/ \mathrm{Na}^{+}$symporters that transport nucleosides against their concentration

*To whom correspondence should be addressed: Laboratory of Chemical Toxicology and Environmental Health, Showa Pharmaceutical University, 3-3165 Higashi-Tamagawagakuen, Machida, Tokyo 194-8543, Japan. Tel. \& Fax: +81-42-7211563; E-mail: ogra@ac.shoyaku.ac.jp gradients. In contrast, ENTs transport nucleosides by facilitated diffusion. ENTs can be further divided into two subclasses depending on their sensitivity to nitrobenzylthioinosine (NBTI). NBTI-sensitive and NBTI-insensitive forms are coded by ENT1 and ENT2 genes, respectively. ENT1 and ENT2 are inhibited by dipyridamole and dilazep. ${ }^{1)}$ On the other hand, CNTs can be divided into three forms. No specific pharmacological inhibitors have been identified for any CNTs so far. It was reported that dipyridamole, a classic NT inhibitor, was useful in enhancing the effectiveness of cancer chemotherapeutic agents, in particular, antimetabolites, based upon the inhibition of the nucleoside salvage pathway. ${ }^{2,3)}$ Hence, the combination of NT inhibitors and antimetabolites is expected to provide more effective and safer cancer chemotherapy in the clinical setting.

Cimicifugoside, a triterpenoid originating from the rhizomes of Cimicifuga simplex (C. simplex), has been used in traditional Chinese medicine as the so-called Cimicifugae rhizoma (Fig. 1). The medicine is prescribed because of its anti- 


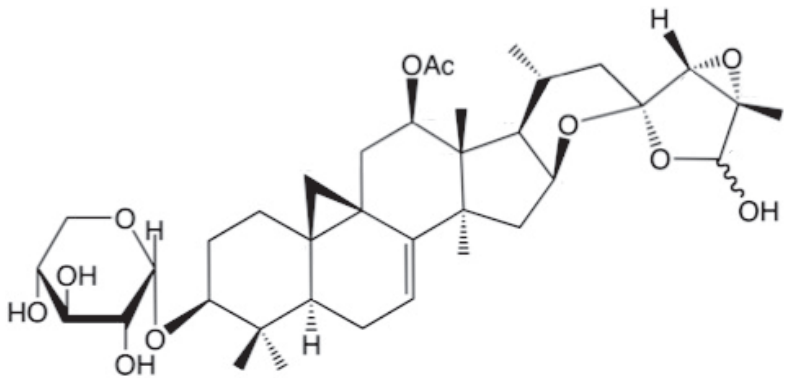

Fig. 1. Chemical Structure of Cimicifugoside

inflammatory, analgesic, and anti-pyretic effects. ${ }^{4)}$ In addition, it has been reported that cimicifugoside selectively inhibits the uptake of nucleosides into phytohematoagglutinin-stimulated human lymphocytes and several malignant cell lines. ${ }^{5,6)}$ Indeed, the uptake of nucleosides, such as uridine, thymidine, and adenosine, but not nucleobases was inhibited by cimicifugoside and its analogs, such as cimicifugenin and bugbanosides $\mathrm{A}$ and $\mathrm{B}$, in a leukemia cell line. ${ }^{7)}$ As the mechanism underlying the inhibition of nucleoside transport by cimicifugoside, it is speculated that cimicifugoside has weak affinity for the binding site of NBTI in ENTs, although the detailed inhibitory mechanism is still unclear. Furthermore, cimicifugoside and its analogs potentiated the cytotoxicity of methotrexate, a folic acid antimetabolite. In our previous study, we demonstrated that the synergic effect of methotrexate and cimicifugoside. ${ }^{7)}$

In this study, we intended to clarify the mechanisms underlying the cell-specific synergic effect of cimicifugoside on the cytotoxicity of methotrexate. We focused on the involvement of NT expression and activity in the cell lines.

\section{MATERIALS AND METHODS}

Chemicals — Cimicifugoside isolated from C. simplex was kindly provided by Professor Genjiro Kusano (Osaka Pharmaceutical University). Methotrexate and thymidine were purchased from Sigma Chemicals (St. Louis, MO, U.S.A.). [Methyl- ${ }^{3} \mathrm{H}$ ]thymidine $(20 \mathrm{Ci} / \mathrm{mmol})$ was purchased from Moravek Biochemicals Incorporated (Brea, CA, U.S.A.). Aquasol-2 was purchased from Packard Company (Groningen, the Netherlands), Roswell Park Memorial Institute (RPMI) 1640 medium was from Nissui Pharmaceutical Company (Tokyo, Japan). Paraffin oil (d 0.86-0.89), creatine kinase, creatine phosphate and adenosine triphos- phate (ATP) were purchased from Wako Pure Chemicals (Osaka, Japan). Silicone oil (d 1.050) was purchased from Aldrich Chemical Company (Milwaukee, WI, U.S.A.). All other chemicals were obtained from standard chemical suppliers at the highest purity available.

Cell Culture — The human promonocytic leukemia cell line U937 and the chronic myelogenetic leukemia cell line K562 were provided by the Cell Resource Center for Biomedical Research (Institute of Development, Aging and Cancer, Tohoku University, Sendai, Japan). Cells were cultured in RPMI 1640 medium supplemented with $5 \%(\mathrm{v} / \mathrm{v})$ heat-inactivated fetal bovine serum (FBS), $60 \mu \mathrm{g} / \mathrm{ml}$ kanamycin and $2 \mathrm{mM}$ L-glutamine (culture medium) at $37^{\circ} \mathrm{C}$ in a humidified atmosphere of $5 \% \mathrm{CO}_{2}$ and $95 \%$ air.

Determination of Cell Growth - To evaluate methotrexate cytotoxicity in the presence of cimicifugoside, 3-(4,5-dimethylthiazol-2-yl)2,5-diphenyltetrazolium bromide (MTT) assay was performed. One thousand cells per well of a 96well flat-bottomed plate were cultured for $5 \mathrm{hr}$ in culture medium $(100 \mu \mathrm{l})$ in a $\mathrm{CO}_{2}$ incubator. The cells were then treated with suboptimal doses of methotrexate in the presence of cimicifugoside for a further $70 \mathrm{hr}$ in a total volume of $200 \mu \mathrm{l}$. Then $100 \mu \mathrm{l}$ of culture medium was removed from each well and $20 \mu \mathrm{l}$ of MTT solution $(6.25 \mathrm{mg} / \mathrm{ml})$ was added. The plates were incubated for an additional $2 \mathrm{hr}$ at $37^{\circ} \mathrm{C}$, and $100 \mu \mathrm{l}$ of lysis buffer consisting of $50 \%$ dimethylformamide and $20 \%$ sodium dodecyl sulfate ( $\mathrm{pH}$ 7.4) was added to dissolve formazan crystals. Absorbance at $570 \mathrm{~nm}$ was determined with a micro-plate reader (Model 3550, BioRad, Hercules, CA, U.S.A.). ${ }^{8}$

In the thymidine rescue experiment, cell growth was evaluated by the dye exclusion method. Five thousand cells per well of a 24-well flat-bottomed plate were cultured for $5 \mathrm{hr}$ in culture medium $(500 \mu \mathrm{l})$ in a $\mathrm{CO}_{2}$ incubator. The cells were then treated with methotrexate in the presence of thymidine for a further $72 \mathrm{hr}$ in a total volume of $1 \mathrm{ml}$. Then, the cells were collected and washed with phosphate buffered saline (PBS). Trypan blue (Trypan blue : RPMI 1640 with $1 \%$ FBS = 1:1) was added to the cell pellet and viable cells were counted. Data are expressed as percentage of control.

Thymidine Uptake Assay — The uptake of radiolabeled thymidine by U937 and K562 was conducted by the inhibitor-oil stop method. ${ }^{9,10)}$ U937 
and $\mathrm{K} 562$ were washed twice with $\mathrm{Na}^{+}$buffer ( $3 \mathrm{mM} \mathrm{K}_{2} \mathrm{HPO}_{4}, 1.8 \mathrm{mM} \mathrm{CaCl}, 1 \mathrm{mM} \mathrm{MgCl}_{2}$, $144 \mathrm{mM} \mathrm{NaCl}, 5 \mathrm{mM}$ glucose, $20 \mathrm{mM}$ Tris- $\mathrm{HCl} \mathrm{pH}$ 7.4) and incubated in the same buffer with or without cimicifugoside at the final cell concentration of $1.1 \times 10^{7}$ cells $/ \mathrm{ml}$ at room temperature for $30 \mathrm{~min}$. To initiate the uptake assay, $100 \mu \mathrm{l}$ of cell suspension was added to $100 \mu \mathrm{l}$ of the $\mathrm{Na}^{+}$buffer containing $\left[{ }^{3} \mathrm{H}\right]$ thymidine $(10 \mu \mathrm{Ci} / \mathrm{ml}, 5 \mu \mathrm{M})$ that was layered over $130 \mu \mathrm{l}$ of oil (mixture of silicone oil and paraffin oil, $22: 3$, v/v) in a 1.5-ml polypropylene microtube at $25^{\circ} \mathrm{C}$. The uptake was stopped by adding $400 \mu \mathrm{l}$ of $250 \mu \mathrm{M}$ cold substrate, and the mixture was immediately centrifuged to precipitate the cells. After aspiration of the aqueous layer, $\left[{ }^{3} \mathrm{H}\right]$ thymidine that was not taken up by the cells was removed by washing gently with water twice and aspirating the oil layer. The cell pellets were lysed with $100 \mu \mathrm{l}$ of 5\% Triton X-100 overnight at room temperature and dissolved in Aquasol-2 scintillation cocktail. Radioactivity was measured with an Aloka LSC-5100 liquid scintillation counter (Aloka, Tokyo, Japan).

RNA Isolation and Reverse Transcription Polymerase Chain Reaction (RT-PCR) - Total RNA was isolated from U937 and K562 using ISOGEN (Nippon Gene, Tokyo, Japan) following the manufacturer's instructions. Complementary DNA was prepared from the total RNA samples using a SuperScript ${ }^{\mathrm{TM}}$ First-Strand Synthesis System for RT-PCR (Invitrogen, Carlsbad, CA, U.S.A.). PCR products were separated by $1.5 \%$ agarose gel electrophoresis. Product bands were visualized and the density of each product band was detected by LAS1000 UV mini (Fujifilm Co., Tokyo, Japan) quantified with Multi Gauge software (Version 3.0; Fujifilm Co.), and expressed in arbitrary units.

\section{Measurement of Thymidine Kinase Activity}

Thymidine kinase (TK) activity was measured following the method of Salama ${ }^{11)}$ and $\mathrm{Hu}$ and Shiota. ${ }^{12)}$ The cells were incubated with or without $1 \mu \mathrm{M}$ cimicifugoside at the concentration of $5.0 \times$ $10^{6}$ cells at $37^{\circ} \mathrm{C}$ for $72 \mathrm{hr}$. Then, the cells were washed with phosphate-buffered saline and sonicated for $24 \mathrm{~s}$ with lysis buffer consisting of $20 \mathrm{mM}$ Tris-HCl pH 7.8 and $1 \mathrm{mM} 2$-mercaptoethanol. The lysed cells were centrifuged at $8000 \times \mathrm{g}, 4^{\circ} \mathrm{C}$ for $20 \mathrm{~min}$ and the supernatant was used as the enzyme source. A $40 \mu \mathrm{l}$ aliquot of the supernatant ( $200 \mu \mathrm{g}$ of protein) was added to $120 \mu \mathrm{l}$ of a mixture containing $150 \mathrm{mM}$ Tris- $\mathrm{HCl}, 16 \mathrm{mM} \mathrm{MgCl}_{2}$, $16 \mathrm{mM}$ ATP, $25 \mathrm{mM} \mathrm{NaF}, 8 \mathrm{mM}$ creatine phos- phate, 1 unit/ml creatine kinase and $0.2 \mathrm{mM}\left[{ }^{3} \mathrm{H}\right]-$ thymidine $(1 \mu \mathrm{Ci} / 120 \mu \mathrm{l})$. The reaction mixture was incubated for $120 \mathrm{~min}$ at $37^{\circ} \mathrm{C}$ and then, a $20 \mu \mathrm{l}$ aliquot of the reaction mixture was applied to diethyl amino ethyl (DEAE) paper (Whatman DE81; Millipore, Billerica, MA, U.S.A.). The DEAE paper was washed with purified water and ethanol, and then the radioactivity of incorporated- $\left[{ }^{3} \mathrm{H}\right]$ deoxy thymidine monophosphate (dTMP) was measured with an Aloka LSC-5100 liquid scintillation counter.

Statistics — The significance of difference between experiment and control was evaluated by the Student's $t$-tests.

\section{RESULTS AND DISCUSSION}

\section{Cell-specific Synergic Effect of Cimicifugoside on Cytotoxicity of Methotrexate}

Although methotrexate showed cytotoxicity to the human chronic myelogenetic leukemia cell line K562 in a dose-dependent fashion, cimicifugoside had no significant effects on K562 (Fig. 2B). On the other hand, cimicifugoside significantly potentiated the cytotoxicity of methotrexate in a dose-dependent fashion in the human promonocytic leukemia cell line U937 (Fig. 2A). These findings coincide with our previous observations. ${ }^{7)}$ In particular, the addition of $1.0 \mu \mathrm{M}$ cimicifugoside to $30 \mathrm{nM}$ of methotrexate considerably decreased cell viability from $47.5 \%$ to $6.38 \%$ However, at $10 \mathrm{nM}$ of methotrexate, the synergic effect of cimicifugoside was marginal. These results indicate that the threshold dose of methotrexate should exceed $10 \mathrm{nM}$ to enable potentiation of its cytotoxic effect by cimicifugoside in U937.

\section{Inhibition of Thymidine Uptake by Cimicifugo- side}

Both cell lines incorporated thymidine in a timedependent manner (Fig. 3). At 30 min after the incubation with cimicifugoside, thymidine uptake was inhibited in both cell lines in a dose-dependent fashion and the inhibition was greater in U937 than in K562. Both U937 and K562 incorporated thymidine, as shown by the radioactive counts per $1 \times$ $10^{6}$ cells of $8.59 \pm 1.98 \times 10^{4}$ and $14.8 \pm 9.06 \times$ $10^{4} \mathrm{dpm}$, respectively, without cimicifugoside treatment. Thus, K562 more efficiently incorporated thymidine than U937.

It was suggested that the addition of cimicifugo- 

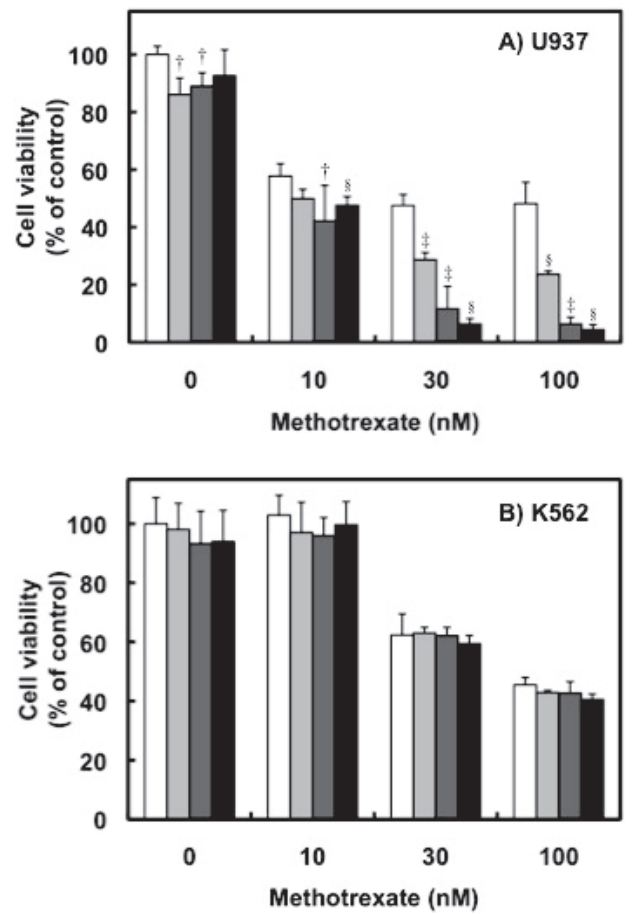

Fig. 2. Effect of Cimicifugoside on the Cytotoxicity of Methotrexate in U937 and K562

U937 (A) and K562 (B) were cultured in the presence of methotrexate at a concentration of $0,10,30$ or $100 \mathrm{nM}$ for $72 \mathrm{hr}$, and this was followed by exposure to cimicifugoside at a concentration of 0 (open columns), 0.1 (light gray columns), 0.3 (dark gray columns) or $1.0 \mu \mathrm{M}$ (closed columns). Cell growth was measured by the MTT assay. Data are means \pm S.D. of quadruplicate determinations and are representative of experiments repeated three times. Stastistical significance is expressed as ${ }^{\dagger} p<0.05,{ }^{\ddagger} p<0.01$, or ${ }^{\S} p<0.001$ by the Student's $t$-test compared with control (without cimicifugoside).

side more markedly potentiated the cytotoxicity of methotrexate in U937 than in K562 because thymidine uptake was more strongly suppressed in U937 than in K562. Hence, we evaluated whether the addition of thymidine improved the viability of U937 damaged by methotrexate. As expected, the cytotoxic effect of methotrexate was significantly ameliorated by the addition of thymidine (Fig. 4). This result reinforces the speculation that the specific synergic effect of cimicifugoside and methotrexate on U937 is a result of the feebler uptake of thymidine by U937 than by K562.

\section{Expression of Nucleoside Transporters}

NT mRNA expression was determined in both cell lines by RT-PCR (Fig. 5). Among the NTs examined in this study, ENT1 showed the highest expression in both cell lines although there was no significant difference in the expression between the two cell lines. On the other hand, the expression of ENT2 in U937 was significantly lower than that in K562. It is known that there are four ENT subtypes
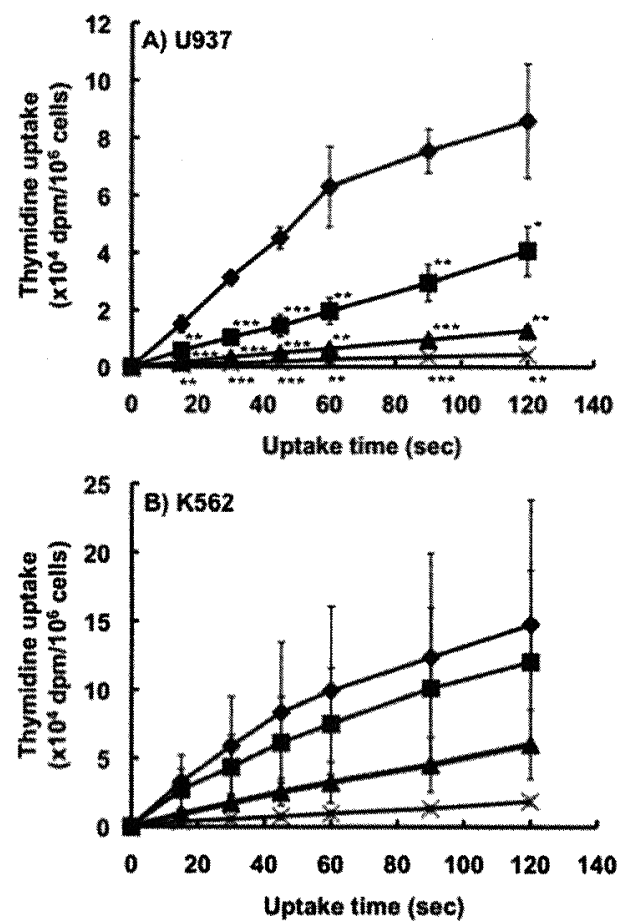

Fig. 3. Effect of Cimicifugoside on Thymidine Uptake in U937 and K562

U937 (A) and K562 (B) were preincubated with cimicifugoside at a concentration of 0 (diamonds), 10 (squares), 30 (triangles) or $100 \mathrm{nM}$ (crosses). Data are means \pm S.D. of six samples tested in duplicate in three separate experiments. Statistical significance is expressed as ${ }^{*} p<0.05,{ }^{* *} p<0.01$ or ${ }^{* * *} p<0.001$, compared with control by the Student's $t$-test.

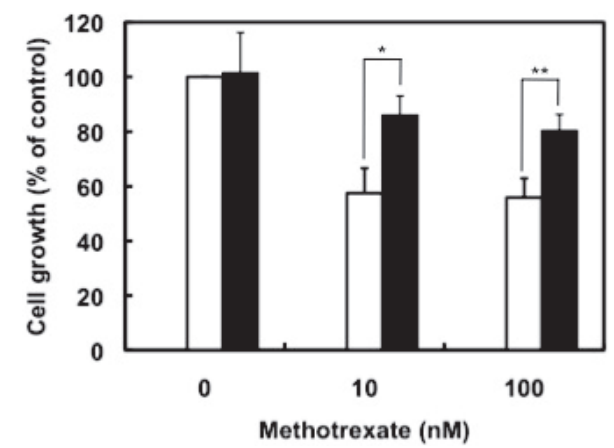

Fig. 4. Effect of Thymidine on the Rescue from the Cytotoxicity of Methotrexate

The cells were treated with methotrexate in the presence (closed columns) or in the absence (open columns) of thymidine. Cell growth was evaluated by the dye exclusion method. Data are means \pm S.D. of quadruplicate determinations and are representative of experiments repeated three times. Statistical significance is expressed as ${ }^{*} p<0.05$ or ${ }^{* *} p<0.01$ by the Student's $t$-test.

in ENT family proteins. ${ }^{13)}$ ENT1 transports nucleosides, whereas ENT2 and ENT3 transport nucleosides and nucleobases. ${ }^{14)}$ Contrary to these ENTs, ENT4 specifically transports adenosine. However, ENT3 and ENT4 are located in the cytoplasm ${ }^{15}, 16$ ) and thus, ENT1 and ENT2 substantially act as the transporters in the salvage pathway. These results 
also support the finding that the thymidine uptake by ENTs, in particular, ENT2, is more strongly suppressed in $\mathrm{U} 937$ than in K562, resulting in the more severe effect of the combination of cimicifugoside and methotrexate.

CNT1 and CNT2 have high substrate specificities to pyrimidine and purine, respectively, whereas CNT3 has less substrate specificity than CNT1 and CNT2. ${ }^{17)}$ Although the expression of CNT3 in K562 tended to be higher than that in U937, no significant differences in the mRNA expressions of CNT family proteins were observed. This indicates that CNTs may not contribute to the cell-specific synergic effect of the combination of cimicifugoside and methotrexate.

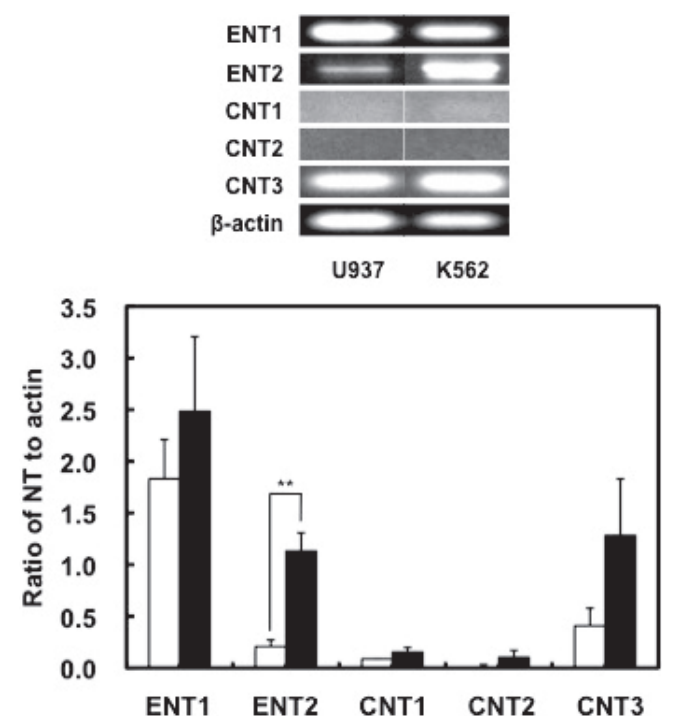

Fig. 5. mRNA Expression of Nucleoside Transporters in U937 and K562

mRNA levels of nucleoside transporters were determined by RTPCR in U937 (open columns) and K562 (closed columns). Data are expressed as means \pm S.D. of three experiments and expressed relative to an endogenous gene ( $\beta$-actin). Statistical significance is expressed as ${ }^{* *} p<0.01$ by the Student's $t$-test.
As shown in Fig. 3, cimicifugoside was able to reduce the thymidine uptake even in K562. However, no synergic effects of methotrexate and cimicifugoside were observed in K562. This observation led us speculate that cimicifugoside has an opposite effect on the reduction of DNA synthesis caused by the inhibition of the nucleoside salvage pathway in K562 specifically. Therefore, the effect of cimicifugoside on TK activity was evaluated.

\section{Effect of Cimicifugoside on Thymidine Kinase Activity}

TK converts thymidine incorporated by NTs into thymidine $5^{\prime}$-phosphate (dTMP). Thus, TK is required for DNA synthesis. TK activity was measured in terms of the conversion of $\left[{ }^{3} \mathrm{H}\right]$ thymidine into $\left[{ }^{3} \mathrm{H}\right] \mathrm{dTMP}$ in U937 and K562. Cimicifugoside significantly increased TK activity in K562 to 1.5 times that of the control, whereas it had no effect on TK activity in U937 (Fig. 6). These results sug-

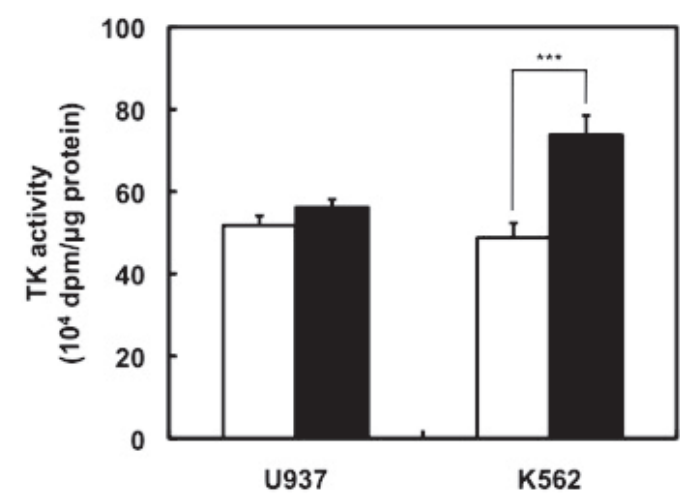

Fig. 6. Effect of Cimicifugoside on TK Activity in U937 and K562

TK activity was measured in the presence (closed columns) or in the absence (open columns). Data are means \pm S.D. of quadruplicate determinations and are representative of experiments repeated three times. Statistical significance is expressed as ${ }^{* * *} p<0.001$ by the Student's $t$-test.

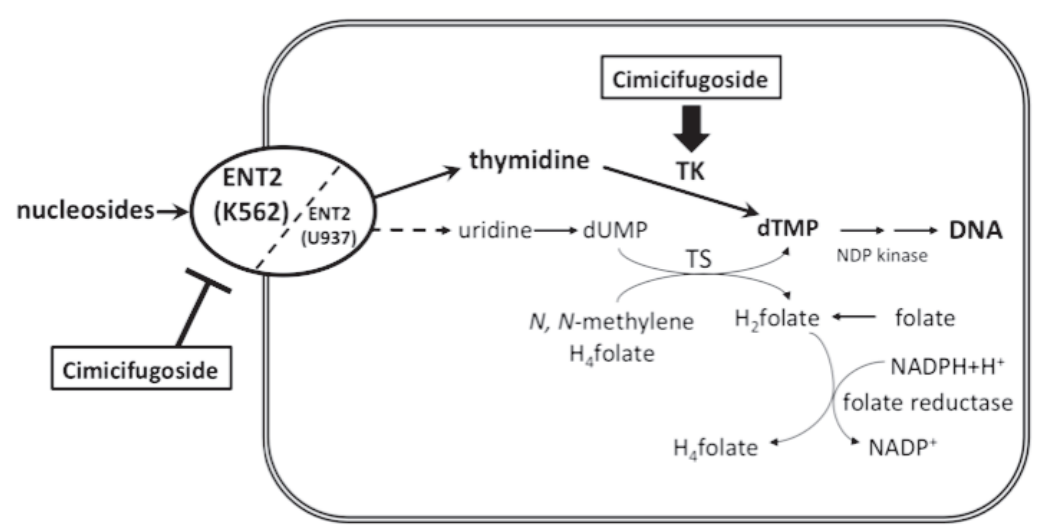

Fig. 7. Proposed Mechanism Underlying the Cell-specific Synergic Effect of Cimicifugoside on the Cytotoxicity of Methotrexate dUMP: deoxy uridine monophosphate. 
gest that the specific effect of cimicifugoside on TK activity promotes dTMP synthesis by methotrexate in K562, resulting in no apparent synergic effects of cimicifugoside and methotrexate. Consequently, the cell-specific effect of cimicifugoside on the cytotoxicity of methotrexate was attributed to the dual function of cimicifugoside.

In conclusions, the results obtained in this study are illustrated in Fig. 7. U937 expressed less ENT2 in the salvage pathway than K562. Cimicifugoside reduced the uptake of thymidine transported by NTs, including ENT2. Thus, the cytotoxicity of methotrexate was more markedly potentiated by cimicifugoside in U937 than in K562. On the other hand, cimicifugoside specifically stimulated TK activity in K562. It is concluded that these effects of cimicifugoside contribute to its synergic effect on methotrexate.

\section{REFERENCES}

1) Baldwin, S. A., Mackey, J. R., Cass, C. E. and Young, J. D. (1999) Nucleoside transporters: molecular biology and implications for therapeutic development. Mol. Med. Today, 5, 216-224.

2) Smith, P. G., Marshman, E., Newell, D. R. and Curtin, N. J. (2000) Dipyridamole potentiates the in vitro activity of MTA (LY231514) by inhibition of thymidine transport. Br. J. Cancer, 82, 924-930.

3) Boyer, C. R., Karjian, P. L., Wahl, G. M., Pegram, M. and Neuteboom, S. T. (2002) Nucleoside transport inhibitors, dipyridamole and p-nitrobenzylthioinosine, selectively potentiate the antitumor activity of NB1011. Anticancer Drugs, 13, 29-36.

4) Kusano, G. (2001) Studies on the constituents of Cimicifuga species. Yakugaku Zasshi, 121, 497-452 (Japanese).

5) Hemmi, H., Kitame, F., Ishida, N., Kusano, G., Kondo, Y. and Nozoe, S. (1979) Inhibition of thymidine transport into phytohemagglutinin-stimulated lymphocytes by triterpenoids from Cimicifuga species. J. Pharmacobiodyn., 2, 339-349.

6) Hemmi, H., Kusano, G. and Ishida, N. (1980) Selective inhibition of nucleoside transport into mouse lymphoma L-5178Y cells by cimicifugoside. $J$. Pharmacobiodyn., 3, 636-642.

7) Yawata, A., Matsuhashi, Y., Kato, H., Uemura, K., Kusano, G., Ito, J., Chikuma, T. and Hojo, H. (2009) Inhibition of nucleoside transport and synergistic potentiation of methotrexate cytotoxicity by cimicifugoside, a triterpenoid from Cimicifuga simplex. Eur. J. Pharm. Sci., 38, 355-361.

8) Hansen, M. B., Nielsen, S. E. and Berg, K. (1989) Re-examination and further development of a precise and rapid dye method for measuring cell growth/cell kill. J. Immunol. Methods, 119, 203 210.

9) Aronow, B., Toll, D., Patrick, J., McCartan, K. and Ullman, B. (1986) Dipyridamole-insensitive nucleoside transport in mutant murine T lymphoma cells. J. Biol. Chem., 261, 14467-14473.

10) Martin, D. and Meckling-Gill, K. A. (1996) Omega3 polyunsaturated fatty acids increase purine but not pyrimidine transport in L1210 leukaemia cells. Biochem. J., 315, 329-333.

11) Salama, S. R. (2000) Use of fusions to human thymidine kinase as reporters of gene expression and protein stability in Saccharomyces cerevisiae. Methods Enzymol., 326, 120-133.

12) $\mathrm{Hu}, \mathrm{N}$ and Shiota, H. (2004) Emergence of resistance to carbocyclic oxetanocin $\mathrm{G}$ in herpes simplex virus type 1 and genetic analysis of resistant mutants. Acta Pharmacol. Sin., 25, 921-926.

13) Baldwin, S. A., Beal, P. R., Yao, S. Y., King, A. E., Cass, C. E. and Young, J. D. (2004) The equilibrative nucleoside transporter family, SLC29. Pflugers Arch., 447, 735-743.

14) Yao, S. Y., Ng, A. M., Vickers, M. F., Sundaram, M., Cass, C. E., Baldwin, S. A. and Young, J. D. (2002) Functional and molecular characterization of nucleobase transport by recombinant human and rat equilibrative nucleoside transporters 1 and 2. Chimeric constructs reveal a role for the ENT2 helix 5-6 region in nucleobase translocation. J. Biol. Chem., 277, 24938-24948.

15) Baldwin, S. A., Yao, S. Y., Hyde, R. J., Ng, A. M., Foppolo, S., Barnes, K., Ritzel, M. W., Cass, C. E. and Young, J. D. (2005) Functional characterization of novel human and mouse equilibrative nucleoside transporters (hENT3 and mENT3) located in intracellular membranes. J. Biol. Chem., 280, 1588015887.

16) Endo, Y., Obata, T., Murata, D., Ito, M., Sakamoto, K., Fukushima, M., Yamasaki, Y., Yamada, Y., Natsume, N. and Sasaki, T. (2007) Cellular localization and functional characterization of the equilibrative nucleoside transporters of antitumor nucleosides. Cancer Sci., 98, 1633-1637.

17) Gray, J. H., Owen, R. P. and Giacomini, K. M. (2004) The concentrative nucleoside transporter family, SLC28. Pflugers Arch., 447, 728-734. 